\title{
MIRADA DESDE LOS ESTUDIOS CULTURALES GTS A LA EDUCACIÓN Y DESARROLLO HUMANO EN EL MARCO DEL CENTENARIO DEL DEPARTAMENTO NORTE DE SANTANDER'
}

(Recibido: Abril 26 de 2011 Aprobado: Julio 05 de 2011)

Óscar Javier Cabeza Herrera** Zully Andrea Velazco Carrillo***

“La enseñanza tiene que dejar de ser solamente una función, una especialización, una profesión y volver a convertirse en una tarea política por excelencia, en una misión de transmisión de estrategias para la vida"

Édgar Morin ${ }^{* * * *}$

\section{Resumen}

El presente artículo da cuenta de la fundamentación del capítulo referente a la educación del Departamento de Norte de Santander en sus cien años. El enfoque es desde la filosofía de la educación y articulado en la perspectiva de los estudios culturales de CTS. Está orientado a la comunidad de maestros del departamento sobre el quehacer educativo, la ciencia, la tecnología y sus posibilidades para el desarrollo humano integral en esta zona del país con su especificidad cultural binacional.

\section{Palabras Clave}

Desarrollo Humano, Ciencia, Tecnología, Sociedad, Educación

\section{LOOK FROM THE GTS CULTURAL STUDIES TO EDUGATION AND HUMAN DEVELOPMENT WITHIN THE FRAMEWORK OF THE GENTENARY OF THE DEPARTMENT OF NORTH SANTANDER}

\section{Alostract}

This article reports on the foundation of the chapter on education in the department of North of Santander in its hundred years. The approach is based on the philosophy of education and articulated from the perspective of cultural studies of STS. It is oriented to the community of teachers of the department of educational work, science, technology and its potential for human development in this area of the country with its binational cultural specificity.

\section{Keywords}

Human Development, Science, Technology, Society, Education

\footnotetext{
* Artículo de reflexión, desarrollado en la Facultad de Artes y Humanidades de la Universidad de Pamplona en el año 2010 y en convenio con la Secretaría de Cultura de la gobernación del departamento Norte de Santander en el marco de la celebración de los Cien años del departamento.

** Óscar Javier Cabeza Herrera es docente-investigador, líder de la línea de investigación en biosofía de la Universidad Santo Tomás, en el grupo de investigación Desarrollo Humano del Departamento de Humanidades, seccional Bucaramanga. Licenciado en Filosofía e Historia, Universidad Santo Tomás; Especialista en Cultura Política y educación, Universidad de Pamplona; Magíster en Bioética, Universidad El Bosque. E-mail: oscar. cabeza@hotmail.com

** Zully Andrea Velazco Carrillo En el año 2010 es asesora de la gobernación de Norte de Santander para el centenario del departamento y bicentenario de Colombia. Docente de la Universidad de Pamplona. Se ha desempeñado como periodista en distintos medios impresos del país: El Tiempo, Vanguardia Liberal y el Diario La Opinión. Comunicadora Social, Universidad de Pamplona; Especialista en Periodismo Electrónico, Universidad Pontificia Bolivariana; Maestrante en Comunicación Digital, Universidad Pontificia Bolivariana. E-mail: zulvel.zulvel@hotmail.com

**** MORIN, E. (2002) Educar en la era planetaria. Barcelona: Gedisa. p. 122
} 


\section{Introducción}

Este artículo corresponde a la fundamentación y contexto de discusión para la construcción del capítulo referente a educación, y que está incluido en el libro del Centenario del Departamento de Norte de Santander. El enfoque que se presenta es desde la filosofía de la educación y articulada en la perspectiva de los estudios culturales de Ciencia, Tecnología y Sociedad. En este orden de ideas, la pretensión de la fundamentación, fue darle a la primera parte del capítulo una entrada reflexiva orientada a la comunidad de maestros del departamento sobre el quehacer educativo, la ciencia, la tecnología y sus posibilidades para el desarrollo humano integral en esta zona del país con su especificidad multicultural binacional. Seguidamente, se delegó el desarrollo del trabajo de una comisión especial de profesionales quien hizo un barrido descriptivo y cuantitativo a la situación de la educación, Ciencia y Tecnología en el Departamento, apartado que no se incluye en el presente artículo.

Indagar sobre la naturaleza y el proceso del quehacer educativo, su implicación con la ciencia y la tecnología, ha de partir de la tensión que hoy propicia la globalización económica y la aparición de lo que se podría llamar como tecnociencia, es decir, el acelerado y engranado desarrollo de la ciencia y la tecnología en un nuevo modo de ser para la misma y que asume la ambigüedad de quien ejerce el liderazgo: si el ámbito reflexivo y teórico de la ciencia; el ámbito práctico y aplicado de las tecnologías o el emergentismo de un nuevo modo de comportamiento tecnocientífico ${ }^{1}$, visto éste como un asunto de necesaria interrelación y que como puente agencia las nuevas exigencias para el desarrollo humano, social, cultural y económico:

Como comienza a ser reconocido comúnmente, lo que con la Modernidad se daba en llamar "ciencia", y por antonomasia la así llamada "ciencia moderna", ha pasado a convertirse en nuestros días-postmodernamente, diríamos- en eso que se llama "tecnociencia" (no, sin duda, con exclusión de lo que clásicamente se ha entendido por ciencia, pero sí a modo de culminación, o último estadio hasta la fecha, de un proceso evolutivo iniciado hace ya unos cuantos siglos y a lo largo del cual se habría operado la transformación de esa ciencia tecnológicamente sustentada, elaborada y legitimada, que es lo que más o menos se quiere decir cuando se dice que la ciencia ha devenido tecnociencia) (Muguerza, 2004, p. 132)

La línea de investigación a la cual responde este escrito es a: Filosofía Práctica del grupo de investigación Dianoia.-Filosofía inscrito en Colciencias con el Código COL0042705 del Departamento de Filosofía de la Universidad de Pamplona, así como al grupo de investigación en educación rural, de la misma institución.

\section{El propósito educativo}

La acción educativa se ha visto condicionada por una doble perspectiva que, por un lado en ruta el avance de este milenio desde el modelo que tiene como único derrotero la competitividad económica y por tanto, el propósito del aparto educativo que responde a esta dinámica, es la inclinación a ser una estricta herramienta de capacitación y formación en destrezas técnicas para la fuerza laboral, operatividad e instrumentos de producción:

[...] si esta tendencia se prolonga, las naciones de todo el mundo en breve producirán generaciones enteras de máquinas utilitarias, en lugar de ciudadanos cabales con la capacidad de pensar por sí mismos, poseer una mirada crítica sobre las tradiciones y comprender la importancia de los 
logros y los sufrimientos ajenos. (Nussbaum, 2010, p. 20)

En este sentido, el acercamiento con lo educativo se reduce a un mínimo contacto de instrucción y aprendizaje que prioriza los componentes de formación funcionales de habilidades específicas por el abandono intencionado de la apropiación de la ciencia, así como de la cultura humana.

Por otro lado, se asume como imperativo el propósito de apropiar la educación como la gran equiparadora social², esencial en el hombre para la realización de su auténtico ser, siendo su finalidad, además de la formación de habilidades específicas, la humanización, socialización y culturización del sujeto humano, capaz de entender las lógicas de desarrollo que presentan los nuevos retos globales y que para el departamento implica la exigencia de entenderse, pensarse, prepararse y actuar con el patrimonio y constructo de ser zona de frontera, lo cual establece su propio ethos ${ }^{3}$, en el modo de ser comportamental, actitudinal y acciones ajustadas a las tensiones producidas por lo tradicional, lo legal y lo moral en las prácticas multiculturales micro y macrosociales:

[...] se refiere a la necesidad de educar para la competitividad y a la vez educar para la humanización y la solidaridad; se construye así otra tensión que implica atender ambos frentes a la vez, es decir, educar desde la racionalidad y el conocimiento científico a la vez que educar y permitir el florecimiento en lo social y en lo individual de lo estético, lo lúdico, lo ético, la imaginación y la fantasía. En una palabra, educar para que las personas sean capaces de potenciar su inteligencia, de cuidar su cuerpo y su espíritu y de amar y disfrutar la vida. (Gutiérrez, Díaz, Gil y Ramírez, 1999, p. 74)

Por tanto, el asunto de la educación, la ciencia y la tecnología hay que hilvanarlo precisamente con el proyecto de qué paradigma de humanidad y su relación con el ambiente se anhela ${ }^{4}$, aunando a esto la condición esencial de realización propia de la naturaleza del hombre en cuanto, éste es indiscutiblemente un proyecto educativo biopsicosocial y espiritual en sí mismo, y que Morin (2001) lo explicita así:

[...] es imposible concebir la unidad compleja de lo humano por medio del pensamiento disyuntivo que concibe nuestra humanidad de manera insular por fuera del cosmos que lo rodea, de la materia física y del espíritu del cual estamos constituidos, ni tampoco por medio del pensamiento reductor que reduce la unidad humana a un substrato puramente bio-anatómico. [...] Paradójicamente, hay un agravamiento de la ignorancia del todo mientras que hay una progresión del conocimiento de las partes. (p. 50)

Sin esta apelación, sería un infortunio pensar la educación, pues se terminaría defendiendo la lectura reduccionista e instrumental del acto educativo, que deslegitima el más alto estándar de formación y desarrollo humano integral como lo es la libertad de su ejercicio ético y su responsabilidad para con las generaciones futuras: "esto quiere decir que antes de preguntar qué poder ejecutivo o qué poder de influencia debe representar al futuro en el presente, está la pregunta de qué inteligencia o qué saber de los valores debe hacerlo" (Jonas, 1995, p. 57), esto connota conciencia plena con su presente, en cuanto puede comprender el inestable equilibrio, profundidad y com- 
plejidad de la existencia, la beneficencia de la naturaleza como compañera y referente de aprendizaje, así como la obligada estimación moral de todo aquello que se precia como vivo en sentido amplio, sin embargo, la especie humana en su proyecto educativo orientado por finalidad distinta, puede desarrollar el más irracional e insensato comportamiento ${ }^{5}$, que termine por recusar su necesaria interrelación en un entorno de auto-ecoevolución ${ }^{6}$ más general:

El problema de su humanización, aunque siempre debió haber sido, desde un punto de vista axiológico, su problema central, asume, hoy, característica de preocupación ineludible. (Freire, 1970, p. 17-18) [...] Educación que, libre de alienación, sea una fuerza para el cambio y para la libertad. La opción, por lo tanto, está entre una "educación" para la "domesticación" alienada y una educación para la libertad. "Educación" para el hombre-objeto o educación para el hombresujeto. (Freire, 1974, p. 27)

"como nunca antes
en la historia,
las sociedades se
están organizando
para acelerar el
cambio tecnológico
y para asimilar la
racionalidad científica
que subyace a tal
cambio"

Así vistas las cosas, el momento histórico coyuntural y estructural que ha vivido el departamento Norte de Santander desde su creación en 1910, es el ser testigo del siglo en el cual la humanidad ha innovado prodigiosamente en el orden de lo cultural su nivel de evolución más complejo, en lo cual no se escinde el acontecer de la ciencia y la tecnología como uno de los productos mejor logrados, pues: "como nunca antes en la historia, las sociedades se están organizando para acelerar el cambio tecnológico y para asimilar la racionalidad científica que subyace a tal cambio" (Gómez, 1999, p. 315), y esto exige para los acuerdos humanos el mayor nivel de civilidad posible y a la altura de tales desarrollos, baste para esto establecer algunos ejemplos apropiados e irrefutables, como lo son: la aviación, el desarrollo de la energía nuclear, la robótica, la biotecnología, la conquista espacial, los ordenadores, las telecomunicaciones, la internet, la microelectrónica, la ingeniería genética, la física de partículas, el cuidado de los arrecifes de coral y la biodiversidad marina, a la par con la proclamación y defensa de los derechos humanos, el derecho internacional humanitario, la dignidad humana y el genoma humano, el empoderamiento de la sociedad civil en relaciones de mayor simetría en el manejo y uso del poder, el emergentismo de las minorías étnicas, la diversidad de género, el fortalecimiento de las democracias sociales, el autocuidado del cuerpo, la perspectiva de la subjetividad, la conciencia ecológica ${ }^{7}$ y ambiental frente al calentamiento global y el prototipo de tecnologías limpias, así como la brecha en la equidad económica y social, lo cual demuestra el tránsito a sociedades multiculturales cada vez más complejas, necesitadas de la construcción de un conocimiento fuerte, que además de los modos explicativos de la realidad por cuenta de la racionalidad logoteorética de la metafísica, o la racionalidad tecnomatemática y positivista de la ciencia, y la instrucción pragmática, sea capaz de autobservar la acción humana, es decir, aunar por el desarrollo en las sociedades inteligentes un conocimiento de qué hacer con el conocimiento que hasta el momento ha desarrollado la humanidad:

[...] a medida que ingresamos a la era del tercer milenio, cada vez estamos más conscientes del dilema formulado por el aumento exponencial en el conocimiento, sin un aumento de la sabiduría necesaria para manejarlo 
[...] que combina la humildad, la responsabilidad y la competencia, que es interdisciplinaria e intercultural, y que intensifica el sentido de la humanidad (Potter, V, 1999, p. 32)

El acento puesto a la construcción de esta sabiduría necesaria, es una tarea y responsabilidad mayor para la acción educativa y por tanto para los maestros, gestores de políticas educativas, instituciones y gobierno que estén pensando la gran exigencia del presente siglo ${ }^{8}$ el cual discurre entre la garantía de igualdad de oportunidades a partir de la aceptación de políticas mínimas sociales y el derrotero del neoliberalismo a través de la competitividad, pues el hombre nortesantandereano como individuo multicultural a través de la instrucción, el aprendizaje y la tradición, se perpetúa como colectivo y vive de acuerdo con el nivel de desarrollo alcanzado:

Las condiciones críticas tanto económicas como ecológicas del sistema mundial, las particularidades de Colombia y la realidad de una creciente brecha entre los países desarrollados y subdesarrollados, requieren una redefinición del desarrollo humano y un nuevo énfasis sobre el conocimiento científico y tecnológico en la educación formal., [...] debe significar un legado humano de información al servicio de estilos de vida inteligentes y garantes de la creatividad humana para futuras generaciones (Llinas, 2000, p. ix-x)

\section{Desarrollo Humano}

En este contexto extraordinario es desde donde ha de interrogarse y agenciar la educación, pues es la cultura la que potencia y forma las estructuras subjetivas del individuo en una constante interacción que reproduce y media modos de ser colectivos, sin que con esto se defienda la idea del individuo como sujeto pasivo y recipiente que se llena, pues:

No es de extrañar, que en esta visión "bancaria" de la educación, los hom- bres sean vistos como seres de la adaptación, de la acomodación. Cuanto más se ejerciten los educandos en el archivamento de los depósitos que les son hechos, tanto menos desarrollarán en sí la conciencia crítica de la que resultaría su inserción en el mundo, como sus transformadores, como sujetos. (Freire, 1970, p. 68)

Por tanto, de lo que trata el propósito del acto educativo es de desarrollar humanamente de manera progresiva las capacidades, las facultades innatas, las aptitudes y la libertad ética ya mencionada. En este sentido, los temas de este siglo son capitales en cualquier agenda, lo cual no sólo garantice la supervivencia colectiva de la especie, como grado mayor de conciencia planetaria, sino que le haga mérito a una especie sensible y racional, que precie su inteligencia en la comprensión de su existencia y la de los otros seres, aprehendiendo y superando las temporalidades de paradigmas reductivistas y objetivantes, el perfeccionamiento en el conocimiento de la sabiduría necesaria para su autogestión y la resolución de problemas de frontera no lineales, en cuanto introduce un modo de ver el mundo de manera más amplia, y que para el ámbito de la comunidad académica y científica se traduciría en la superación de la interdisciplinariedad, dándole espacio al trabajo en red, agenciada desde nodos de conocimiento que conjugan lo que en otrora época serían intereses particulares y parcelados para redignificarlos en intereses comunes propias a una cultura plural, diversa moralmente y ávida de mayores resultados exitosos:

[...] en nuestra cultura occidental estamos lanzados en la idea de que tenemos que controlar la naturaleza, porque creemos que el conocimiento permite el control, pero de hecho no es así, el conocimiento no lleva al control. Si el conocimiento lleva a alguna parte, es al entendimiento, a 
la comprensión, y esto a una acción armónica y concertada con lo otro o el otro (Maturana, 2002, p. 61)

Tal es el caso de la educación, amplio y complejo fenómeno social para el conocimiento, el cual exige a la pedagogía dialogar, articular e incorporar los saberes de otras disciplinas afines:

La psicología adquiere sentido para la pedagogía si tiene en cuenta a la educación, o mejor, la situación educativa que se da entre dos personas, como objeto de atención. [...], una psicología que quiera ser de importancia para la pedagogía tiene que resultar entonces del encuentro pedagógico. No le basta simplemente hablar de desarrollo o de aprendizaje, tiene que surgir de la situación educativa misma, con lo que se vuelve necesario tener un acercamiento a las problemáticas educativas y pedagógicas (Runge, 2005, p. 62)

Así mismo, en este carácter interdisciplinario, Runge destaca el trabajo en construcción que viene haciendo la antropología pedagógica desde comienzos del siglo $X X, y$ que asume como presupuestos fundamentales de indagación al ser humano como ser carente, ser no especializado y formable, y como un ser abierto al mundo. A partir de los mismos ha de interrogar: "por los aspectos -subjetivos y objetivos, capacidades y contenidos culturales, entre otros- que humanizan al hombre, por las posibilidades o no de su educación y por lo que, en consecuencia, una educación formativa y humanizadora ha de significar" (p. 50)

Este diálogo de saberes ubica a la educación como un problema de frontera, en cuanto la misma no se agota en el puro quehacer del pedagogo, y en última instancia adquiere sentido si la educación le permite a cualquier sujeto una mayor comprensión de la realidad, la superación ilustrada de certezas fijas y el vínculo: “[...] en la construcción de un mundo de acciones conmensurables con nuestro vivir" (Maturana, 2002, p. 61)

Así, al ser un problema de frontera ha de reconocer en la acción mediadora de la educación la unificación de la historia universal, regional y local con los requerimientos del presente y las prospectivas de futuros posibles, que ha de aleccionar en los individuos la no repeticencia de las experiencias erróneas de la especie, así como la equiparación y empoderamiento en los nuevos miembros de una comunidad, del cúmulo cultural humano en la experiencia colectiva del aprendizaje, perspectivas, apropiaciones, representaciones, aprehensiones, cosmovisiones, $y$ demás..., que del mundo y sus interacciones se hayan elaborado, en este sentido, se ha de reconocer que la educación, de la mano de la psicología experimental ha obviado la naturaleza social del aprendizaje. En respuesta, la etnografía como desarrollo de la antropología, se alza como la manera más apropiada para investigar el aprendizaje, con lo cual se espera superar el reduccionismo del rendimiento instrumental medido a través de pruebas y test, para darle su lugar al desarrollo de las capacidades, actitudes y productividad del sujeto educable:

Todos los educadores deben reconocer que las teorías del aprendizaje que sustentan los programas mecánicos y las pruebas repetitivas de la educación contemporánea son inconducentes, artificiales y peligrosas. El aprendizaje es una actividad social, y sus aspectos más importantes desde el punto de vista del que aprende son las otras personas que están en la situación, el -club- al que los aprendientes deben ingresar (Smith, 1994, p. 132)

Hoy la acción educativa es aventajada didácticamente con la incursión de las Tecnologías de la Información y Comunicación (TIC), pues a través del uso de estos dispositivos mediáticos y sólo así, auxilian una mayor eficiencia y maximi- 
zación del tiempo, interacción continua entre las partes fuera del aula en una constante retroalimentación, progresividad en el acceso a los datos e información y mayor profundidad en la especificidad de los saberes, mayor rapidez en el procesamiento de la información, así como la ampliación de la capacidad de almacenamiento de datos, un comportamiento sistémico en un constante input y output que reprograma y reordena los datos. Sin embargo, tomar las TIC como finalidades y bajo la instrumentalización educativa refuerza la: "equivocada -individuaciónque se ve todavía más facilitada hoy, cuando los alumnos pueden trabajar en sus propias terminales de computadoras, protegidos los unos de los otros" (129)

De lo que se trata es de no anular el aprendizaje social dado a través de las irrenunciables relaciones personales, la constante comunicación que se ejerce en el acto educativo entre maestrosestudiantes, orientada a esta época de autorresponsabilidad y autonomía en la propia formación de la subjetividad y la experiencia de la vida colectiva en un entorno de autobservancia ${ }^{9}$ cada vez más entramado entre naturaleza, artificialidad, ciencia, tecnología, economía, política y ética.

A los educadores nortesantandereanos, en este proceso de instrucción y aprendizaje social les implica sostener un conversatorio permanente con la historia, sus desarrollos y prospectivas, en cuanto:

Los educadores somos modestos discípulos de los grandes Maestros de la humanidad; los leemos, los interpretamos, nos instruimos, nos nutrimos de su ciencia o de su arte; nos deleitamos con sus enseñanzas, hasta donde podemos seguirlas, $y$, con sumo respeto y admiración les damos vida, amplificamos sus ecos y de ellos, con mucha emoción, hacemos partícipes a nuestros estudiantes. (Osorio, 2006, p. 216)
El diálogo es entonces la base de esta relación comunicativa, pues a través de la palabra sea oral, escrita o simbólica y mediada por los sistemas de almacenamiento se expresan significados tanto sensibles como lógicos para la comprensión del mundo, se forja la libertad, se empodera al sujeto, se supera la individualidad, y se ajustan los actos cooperativos $^{10}$ entre la especie:

Las conversaciones, como un entrelazamiento del emocionar y el "lenguajear" en que vivimos, constituyen y configuran el mundo en que vivimos como un mundo de acciones posibles en la concreción de nuestra transformación corporal al vivir en ellas. Los seres humanos somos lo que conversamos, es así como la cultura y la historia se encarnan en nuestro presente. [...] De hecho, nuestra única posibilidad de vivir el mundo que queremos vivir es sumergirnos en las conversaciones que lo constituyen como una práctica social cotidiana en una continua conspiración ontológica que lo trae al presente. (Maturana, 2002, p. 106-107)

Sin embargo, como cada época exige la búsqueda y establecimiento de nuevas propuestas educativas ${ }^{11}$ que permitan responder al propósito antropológico de la formación y desarrollo integral del sujeto y su comprensión del lugar que ocupa en el entramado de la vida, visibiliza la dura y exigente tarea por realizarse en las instituciones que por misionalidad dedican su quehacer especializado a la instrucción y el aprendizaje como actividad social y conscientemente planificada:

Lo anterior exige una restructuración y revolución educativa que genere un nuevo ethos cultural que haga posible la maximización de las capacidades intelectuales y organizativas de los colombianos. La manera innovativa de entender y actuar -no el simple saber y hacer- debe permitir que se adquieran 
nuevas habilidades humanas, basadas en el desarrollo de múltiples saberes y talentos, tanto científicos como artísticos y literarios, y de nuevas formas de organización productiva. (Llinás, 2000, p. 11)

Este acontecer en las prácticas educativas, han de verse como el resultado de las exigencias sociales que la humanidad ha vivido, concordante a los intereses de cada momento coyuntural y pertinente a un proceso estructuralmente progresivo, que demuestra en cada época la necesaria intervención del acto educativo institucional en el desarrollo humano, pasando de escuelas opresoras a espacios de formación de la sensibilidad, la razón y la libertad, a través de lo que hoy se pretende consolidar como dialogantes ${ }^{12}$ entre la consolidación de nuevas interrelación y superación de la tensión entre los actores educativos y sus respectivas generaciones: maestro-estudiante y que a su vez ha de reconocer la diversidad y pluralidad necesaria en los procesos de inclusión y formación de democracia:

[...] la tarea de formación humana es el fundamento de todo el proceso educativo, ya que sólo si ésta se completa, el niño o niña podrá vivir como un ser socialmente responsable y libre, capaz de reflexionar sobre su quehacer y su reflexionar, capaz de ver y corregir errores, capaz de cooperar y de vivir una conducta ética porque no desaparece en sus relaciones con los demás (Maturana, 1995 , p. 16)

Sin embargo, no se debe perder la perspectiva que plantea los intereses económicos privados y políticos del mundo de hoy y que, por tanto, han inclinado la educación al sólo acto externo de instrucción de autómatas, instrumentos de producción, tecnicismos, bajo la complacencia de la sociedad, las empresas, el Estado, los gobernantes tecnócratas, los maestros e instituciones de educación que han dejado de lado el deber y compromiso insoslayable de cualquier sistema educativo de estimular el aprendizaje, formar actitudes y capacidades favorables en el individuo en todo momento de su vida, sin discriminar en que etapa evolutiva de desarrollo se encuentre ${ }^{13}$, en cuanto: “[...] la educación es un proceso abierto y constante, que compromete a todas las personas, los estamentos y las instituciones" (Gómez, 1999 , p. 29)

Desde el enfoque de los estudios culturales en CTS, la educación ha de favorecer el equilibrio en el sujeto biopsicosocial y espiritual el humanismo con los saberes específicos de las tecnociencias, de tal suerte que la instrucción para la inmediatez competitiva no le sacrifique al sujeto la sensibilidad y su libertad, la apropiación de valores individuales y sociales, así como las competencias y habilidades instrumentales con lo cual no se sacrifique lo uno por lo otro, o dándole mayor fuerza a lo uno que a lo otro en el entendido que:

[...] el más influyente precursor intelectual del STS fue C.P. Snow, quien en la conferencia Rede de 1959, dictada en Notre Dame, afirmó que en nuestra sociedad existía una creciente separación entre-dos culturas (incomunicadas)-, una formada por científicos y otra por humanistas" (Cutcliffe, 1990, p. 22 En: Medina)

Por tanto, el aporte de la educación para la realización de cualquier proyecto de vida ha de incluir como derrotero la felicidad individual, la solidaridad y la vida futura de la especie, que le permita a cualquier sujeto imaginar la experiencia del otro y su dignidad, en cuanto reconoce en la vida social la fragilidad y vulnerabilidad de cualquier sujeto humano, sin dejar de lado la formación teórica de la ciencia, la práctica y lo experimental. Así no se desconoce la necesidad inmediata de un dominio específico, una habilidad, 
un saber, arte u oficio especializado, y que lo perfila desde los primeros años de vida de la mano del mentor hasta la posterior autogestión del aprendizaje que le permita su desempeño individual y social en la edad productiva.

A la primera institución natural que culturiza y socializa al individuo, tal como lo es la familia le obliga trazar nuevas lógicas en su acento formativo, en cuanto con la crisis de la modernidad ha sufrido fuertemente un proceso sistemático de redireccionamiento, el cual ha desintegrado y debilitado, tal como argumenta Maturana (1995) el "ámbito de convivencia generado por las personas bajo la pasión de vivir juntos" (p. 119)

Esta crisis a la cual asiste la familia esta apalancada por los fuertes prototipos de individualidad, las necesidades de consumo y producción que obligan la inserción de ambos padres en el mercado económico, así como la ausencia de uno o ambos padres en el hogar, lo cual socava la familia fundada "en el amor como condición de posibilidad" y su realización "desde el deseo de la cercanía en la confianza y aceptación mutuas como un espacio de colaboración en el compartir en la sensualidad, la ternura y la sexualidad" (p. 119). La consecuencia directa de esto en el ámbito educativo será la pérdida y/o ausencia del cultivo de la responsabilidad en el núcleo familiar para con el cumplimiento de los deberes y obligaciones educacionales, así como la convivencia social: "Si no hay amor, si no nos movemos en el amor en nuestros encuentros con otros, no hay fenómeno social, y la opción es la indiferencia que permite cualquier mecanismo de negación del otro, desde la competencia al odio" (Maturana, 1999, p. 107-108)

Considerar desde este reduccionismo y visión posmoderna que la institución escolar puede sustituir la relación de amor y afecto que en los niños naturalmente determinarían sus padres, es una cuestión que ninguna institución y sistema educativo formal podrá remplazar, así estos perseveren, se matriculen y comprometan en un esfuerzo sostenido con el desarrollo humano como ser integral, asunto que ha motivado propuestas filosóficas, epistemológicas, metodológicas, diseños curriculares y evaluaciones al interior del sistema escolar por cuenta de los grandes pedagogos ${ }^{14}$.

\section{Conclusión}

Dar razón en una sociedad altamente compleja a la bastedad del conocimiento y el avance acelerado de las tecnociencias, precisa equiparar ${ }^{15}$ la competitividad y la humanización en la escogencia de campos concretos de trabajo, en el cual se desarrolle las capacidades y cualidades del individuo y su exigencia ética para con el futuro, así muchos terminen desempeñándose circunstancialmente en asuntos demasiado pragmáticos, lo cual no implica que la multiplicidad de la cultura y la especificidad del trabajo han de verse de manera incompatible, ya que dedicarse sólo a lo específico hace asumir posturas reduccionistas y perder el horizonte de sentido del entramado de la vida:

Surgen, entonces, diversos interrogantes: en el mundo neoliberal y desde un país como el nuestro, la educación tiene como finalidad construir igualdad de oportunidades? O, sólo busca calificar la fuerza laboral para el mundo de la revolución científica y tecnológica? Qué posibilidades reales tiene de construir igualdad, de convertirse en el gran equiparador social, cuando el Estado la asume sólo en condiciones marginales y cuando para él prevalece el oponerse 
a tono con las exigencias del FMI, aún a costa de sacrificar su enunciado como Estado Social de Derecho y las concomitantes realizaciones en términos de derechos económicos sociales y culturales, de manera específica, en términos de salud, educación y trabajo? [...] (Gutiérrez, Díaz, Gil, Ramírez, 1999, p. 56 y 59$)$

\section{Notas}

${ }^{1}$ En la obra del filósofo desde la competencia al HOTTOIS, Gilbert. (1991). El paradigma bioético: Una ética para la tecnociencia. Traducción de M. Carmen Monge. BarceIona: Ed, Anthropos., se puede encontrar una rica discusión del término tecnociencia, ajustado el mismo al contexto de la sociedad contemporánea entre el poder y hacer que hoy reviste la misma, y que supera la clásica escisión entre la teoría (ciencia) y la técnica, sobrepasando la tradición logoteorética greco-romana de carácter contemplativa y la tecnomatemática como modelos de reconstrucción de lo real propio a la idea de progreso racionalista de la ilustración, derivada en el positivismo del siglo XIX y XX.

2 Lectura del capítulo El contexto: el mundo de la globalización En: GUTIÉRREZ, Ana; DÍAZ, Guillermo; GIL, Carlos, y RAMÍREZ, Ángel. (1999). Pamplona Ciudad Educadora. Pamplona: Ed, Ideas Litográficas.

${ }^{3}$ Se recomienda en la lectura de MALDONADO, Carlos. (2002). Filosofía de la Sociedad Civil. Bogotá: Siglo del Hombre Editores, la revisión al concepto de Lógica de contrafácticos como herramienta del pensamiento para hacer prospectiva de escenarios futuros posibles.
${ }^{4}$ La obra de CAPRA, Fritjof. (2003). Las conexiones ocultas: Implicaciones sociales, medioambientales, económicas y biológicas de una nueva visión del mundo. Traducción de David Sempau. Barcelona: Ed, Anagrama., permite apropiar una lectura más holística de la relación ineludible de los seres vivos y las posibilidades de la continuidad de la vida. Este enfoque que podría anunciarse como sistémico más que complejo, es una excelente herramienta de trabajo con lo intelectual para abrir perspectivas por la manera como ha de apropiarse este nuevo rol de la especie humana y sus modos de comportamiento para con la vida.

5 Con la lectura de FUKUYAMA, Francis. (2002). Our posthuman future. Consequences of the biotechnology revolution. Nueva York: Ferrar Straus and Giroux. [Trad. Paco Reina]. El fin del Hombre: Consecuencias de la Revolución Biotecnológica. Barcelona: Ediciones B., se pretende reconocer que si bien es cierto las tecnociencias traen sus bondades y resulte ser menos poderosa de lo que se visualiza, o que a la hora de aplicar la misma su uso sea sensato y responsable, no agota la posibilidad de un uso inadecuado de estos desarrollos, lo cual derivaría en: a) la posibilidad que la misma altere la naturaleza humana, y nos presente la condición evolutiva de una naturaleza "posthumana", y b) las consecuencias nocivas para la naturaleza de la propia política, y específicamente la democracia liberal.

${ }^{6}$ En la obra de KAUFFMAN, Stuart. (1995). At Home in the Universe: The Search for the Laws of Self-Organization and Complexity. New York: Oxford University Press., nos presenta una excelente 
argumentación sobre los orígenes de la vida y de organización molecular, vista la misma desde la nueva biología de la ciencia de la complejidad, que expone lo que él llama el "orden gratuito" en las redes construidas al azar y en las que se exhibe una suerte de auto-ecoorganización de la vida. Por tanto, esta obra lo que busca es explicar las leyes de la auto-organización de lucha individual de cada especie por un lugar en el nicho, la cooperación ciega entre las especies en esa lucha y la evolución compleja de todo el entramado.

7 La obra de LEOPOLD, A. (2005). Una ética de la tierra. (2da Ed: Jorge Riechmann) Madrid: Catarata., hace un llamado de atención a mediados del siglo $X X$ sobre la necesidad de una ética que superara al individuo, visto sólo como miembro de una comunidad de partes interdependientes, recusando por una ética de la tierra, que sencillamente, extienda las fronteras de la comunidad para incluir los suelos, las aguas, las plantas y los animales; dicho de un modo colectivo, la tierra (p. 134-135). Otra obra interesante de revisión es LOVELOCK, James. (2007). La venganza de la tierra: la teoría de gaia $y$ el futuro de la humanidad. Chile: Ed. Planeta., en torno a las complicaciones ambientales que atraviesa la humanidad.

${ }^{8}$ WILCHES, G. (1993). Consideraciones para una política socio-ambiental sobre recursos genéticos y biodiversidad. Santafé de Bogotá: Ed., Cipav.

${ }^{9}$ En la obra de MATURANA, Humberto y PORKSEN, Bernhard. (2008). Del ser al hacer: Los orígenes de la biología del conocer. [Traducción de Luisa Ludwig]. Buenos Aires: Ed. Granica., se aborda la autobservancia desde la biología, argumentando al final de todo este proceso como aparece la ética.

${ }^{10}$ AXELDROD, Robert (1984) La Evolución de la Cooperación. España: Alianza Editorial.
${ }^{11}$ Con sus propias tensiones y modelos educativos, que ha ejercido su estatuto epistemológico desde perspectivas tradicionales o lo que con Zubiría se conoce como paradigma heteroestructurante ajustado desde el primado del maestro hasta aquel paradigma autoestructurante que enfoca su interés en el desarrollo natural, experimental, pragmático, social, cognitivo y de procesos mentales del estudiante, tal como la historia de la pedagogía y teorías del aprendizaje lo han registrado. De ZUBIRÍA, Julián; RAMíREZ, Alberto y otros. (2008) El Modelo Pedagógico predominante en Colombia. Bogotá: Instituto Alberto Merani.

12 Ibid.

${ }^{13}$ ARENDT, Hannah. (1998). La condición humana. Traducción de Ramón Gil Novales. Barcelona: Ed. Paidós.

${ }^{14}$ Para hacer un barrido de la historia de la pedagogía y sus proyectos educativos se recomienda la lectura de la obra de ABBAGNANO, Nicola y VISALBERGHI, A. (1996). Historia de la pedagogía. México D.F.: Ed. FCE.

${ }^{15}$ Se recomienda la lectura de NAGEL, Thomas (1996). Igualdad y Parcialidad: Bases éticas de la teoría política. Barcelona: Paidós., en la cual se aborda los niveles morales inaceptables de desigualdad económica y social por cuenta del capitalismo, la cual ha de superarse desde la relación de cada sujeto consigo mismo. Otra obra de referencia es CAMPS, Victoria (1994). La igualdad y la libertad. En Amelia Valcárcel (compiladora), El concepto de igualdad. Madrid: Editorial Pablo Iglesias.

\section{Referencias}

ABBAGNANO, Nicola y VISALBERGHI, A. (1996). Historia de la pedagogía. México D.F.: Ed. FCE.

ARENDT, Hannah. (1998). La condición humana. [Trad. de Ramón Gil Novales]. Barcelona: Ed. Paidós.

AXELDROD, Robert (1984) La Evolución de la Cooperación. España: Alianza Editorial.

CAMPS, Victoria (1994). La igualdad y la libertad. En Amelia Valcárcel (compiladora), El concepto de igualdad, Madrid: Editorial Pablo Iglesias.

CAPRA, Fritjof. (2003). Las conexiones ocultas: Implicaciones sociales, medioambientales, económicas y biológicas de una nueva visión de mundo. [Trad. David Sempau]. Barcelona: Ed, 
Anagrama.

DE ZUBIRÍA, Julián; RAMÍREZ, Alberto y otros. (2008) EI Modelo Pedagógico predominante en Colombia. Bogotá: Instituto Alberto Merani.

FREIRE, Paulo. (1974). La educación como práctica de la libertad. 15 ed., Argentina: Siglo veintiuno editores.

FREIRE, Paulo. (1970). Pedagogía del Oprimido. Bogotá: Ed. América Latina.

FUKUYAMA, Francis. (2002). El fin del Hombre: Consecuencias de la Revolución Biotecnológica. [Trad. Paco Reina]. Barcelona: Ediciones B.

GÓMEZ, Hernando. (1999). Educación: La agenda del siglo XXI. (2da, reimpresión) Colombia: Tercer mundo editores.

GUTIÉRREZ, Ana; DÍAZ, Guillermo; GIL, Carlos, y RAMÍREZ, Ángel. (1999). Pamplona Ciudad Educadora. Pamplona: Ed, Ideas Litográficas.

HANS, Jonas. (1995). El Principio de Responsabilidad: Ensayo de una ética para la civilización tecnológica. [Trad. Javier Ma. Fernández Retenaga]. Barcelona: Herder.

HOTTOIS, Gilbert. (1991). El paradigma bioético: Una ética para la tecnociencia. [Trad. M. Carmen Monge]. Barcelona: Ed, Anthropos.

KAUFFMAN, Stuart. (1995). At Home in the Universe: The Search for the Laws of Self-Organization and Complexity. New York: Oxford University Press.

LOVELOCK, James. (2007). La venganza de la tierra: la teoría de gaia y el futuro de la humanidad. Chile: Ed. Planeta.

LLINÁS, Rodolfo. (2000) El reto: educación, ciencia y tecnología. Bogotá: Tercer mundo editores.

MACHADO, Ineida. (1999). Bioética y Biopolítica: una complementariedad filosófica necesaria en el derecho a la no exclusión. En Cuadernos de filosofía política ética y pensamiento filosófico latinoamericano. Venezuela: Universidad de los Andes.

MALDONADO, Carlos. (2003). Biopolítica de la guerra. Bogotá: Siglo del Hombre Editores.

MALDONADO, Carlos. (2002). Filosofía de la Sociedad Civil. Bogotá: Siglo del Hombre Editores.

MATURANA, Humberto y PORKSEN, Bernhard. (2008). Del ser al hacer: Los orígenes de la biología del conocer. [Trad. Luisa Ludwig]. Buenos Aires: Ed. Granica.

MATURANA, Humberto. (2002). Emociones y lenguaje en educación y política. (11 ed.,). España: Dolmen.

MATURANA, Humberto. (1999). Transformación en la convivencia. Chile: Dolmen.

MATURANA, Humberto. (1995). Formación humana y capacitación. Chile: Dolmen.

MEDINA, M., y KWIATKOWSKA, T., (eds.), (2000). Ciencia, tecnología/naturaleza, cultura en el siglo XXI. Barcelona: Anthropos/UAM.

MEDINA, M., y SANMARTíN, J., (eds.), (1990). Ciencia, tecnología y Sociedad: estudios interdisciplinarios en la universidad, en la educación y la gestión pública. Barcelona: Anthropos.

MEJÍA, Marco R. (1997). Reconstruyendo la cultura escolar. Bogotá: Cinep.

MORIN, Édgar. (2002) Educar en la era planetaria. Barcelona: Gedisa

MORIN, Édgar. (2001). Los siete saberes necesarios para la educación del futuro. Bogotá: Cooperativa Editorial Magisterio.

MUGUERZA, Javier. (2004) ¿Convicciones y/o responsabilidades? (tres perspectivas de la ética en el siglo XXI). Revista de Investigaciones, UNAD, vol. III. No. 1 (Junio).

NAGEL, Thomas (1996). Igualdad y Parcialidad: Bases éticas de la teoría política. Barcelona: Paidós.

OSORIO, Amado. (2006). Filosofía, filosofía de la educación y didáctica de la filosofía. Manizales: Ed. Universidad de Caldas.

RUNGE, Andrés. (2005). La orientación fenomenológica del pensamiento de Otto Friedrich Bollnow y de Martinus Jan Langeveld, dos de los fundadores de la antropología pedagógica alemana. Revista Educación y Pedagogía, Medellín, Universidad de Antioquia, Facultad de Educación, vol. XVII, núm. 42, (mayo-agosto), pp. 47-66.

SMITH, Frank. (1994). De cómo la educación apostó al caballo equivocado. [Trad. Isabela Stratta]. Buenos Aires: Ed. Aique.

VASCO, Carlos; BERMÚDEZ, Ángela y Otros. (1999). EI saber tiene sentido: Una propuesta de integración curricular. Bogotá: Cinep.

WILCHES, G. (1993). Consideraciones para una política socio-ambiental sobre recursos genéticos y biodiversidad. Santafé de Bogotá: Ed. Cipav. 